\title{
The Effect of Speaking Valves on ICU Mobility of Individuals With Tracheostomy
}

\author{
Camila Ceron, Danielle Otto, Alana Verza Signorini, Marco Colomé Beck, Marcio Camilis, \\ Daniel Sganzerla, Régis Goulart Rosa, and Cassiano Teixeira
}

\begin{abstract}
BACKGROUND: Early mobilization is part of the rehabilitation process for critically ill patients and is currently considered a means of preventing ICU-acquired muscle deterioration and worsening of physical function. We sought to determine whether the use of speaking valves in tracheostomized patients would improve their mobility. We evaluated the changes in mobility performance with the use of speaking valves in tracheostomized subjects. METHODS: We performed a cohort study of a series of subjects who were tracheostomized and were being weaned from mechanical ventilation between April 2016 and May 2018. The subjects were those able to tolerate a speaking valve for a minimum of $30 \mathrm{~min}$. Demographic data, comorbidities, cause of ICU admission, days in the ICU, duration of mechanical ventilation before tracheostomy, and days free from mechanical ventilation before tracheostomy were collected. Mobility status was evaluated using daily measurements of the Perme Intensive Care Unit Mobility Score. RESULTS: During the study period, 63 patients were tracheostomized. Patients with deficiencies in language $(n=2)$ or cognitive deficits $(n=36)$ and patients in exclusive palliative care $(n=7)$ were excluded. Eighteen subjects were enrolled in the study. The mean age of the subjects was $64.6 \pm 14.2 \mathrm{y}(55.5 \%$ were male $)$, and the most common reason for ICU admission was pneumonia $(n=7 ; 38.8 \%)$. Perme scores increased from 11.3 (interquartile range 10.1-12.0) on the day before initiation of the speaking valve to 18.2 (IQR 16.2-20.1) immediately after the initiation of a speaking valve $(P<.01)$. These changes were maintained during all periods of speaking valve use. CONCLUSIONS: The use of speaking valves in tracheostomized subjects improved mobility. Key words: speaking valves; tracheostomy; mechanical ventilation; early mobilization. [Respir Care 2020;65(2):144-149. (c) 2020 Daedalus Enterprises]
\end{abstract}

\section{Introduction}

Early mobilization is part of the rehabilitation process for critically ill patients and is currently considered a means of preventing ICU-acquired muscle weakness and deterioration of physical function. ${ }^{1,2}$ Only a few days of critical

\footnotetext{
Ms Ceron, Ms Otto, Ms Signorini, Mr Beck, Mr Camilis, and Mr Sganzerla, as well as Drs Rosa and Teixeira, are affiliated with the ICU of Moinhos de Vento Hospital, Porto Alegre, Brazil. Dr Teixeira is also affiliated with the ICU of Clínicas Hospital, Porto Alegre, Brazil.

The authors have disclosed no conflicts of interest.
}

Correspondence: Cassiano Teixeira MD PhD, Moinhos de Vento Hospital, ICU Department, 3rd Floor, 910 Ramiro Barcelos St, Porto Alegre, Brazil. E-mail: cassiano.rush@gmail.com.

DOI: $10.4187 /$ respcare 06768 illness can lead to significant loss of lean body mass despite optimal nutrition, causing profound weakness (catabolism), recurrent nosocomial infections (immunosuppression), poor wound healing, and recurrence of infections. ${ }^{3,4}$ Mobilization has been associated with decreased duration of mechanical ventilation. ${ }^{2,4-6}$ Observational studies and small randomized clinical trials have shown that early mobilization (ie, starting within $72 \mathrm{~h}$ of ICU admission) is an important and feasible strategy to prevent ICU-acquired weakness, with improved functional outcomes at hospital discharge, increased ventilator-free days, and reduction in the duration of delirium. ${ }^{7,8}$ However, recent systematic reviews have not demonstrated this significant effect on functional recovery or quality of life. ${ }^{2,9}$

A speaking valve is a one-way valve that blocks air flow from exhalation in a tracheostomized patient and redirects it through to the upper airway to enable functional use of the glottis. ${ }^{10}$ The valve is designed to be inserted in align- 
ment with the ventilator or in T-tubing and requires the tracheostomy cuff to be deflated to allow air to bypass the tracheostomy cannula and be exhaled through the larynx. ${ }^{11,12}$ Speaking valves have the potential to improve

\section{See the Related Editorial on Page 269}

respiratory mechanics ${ }^{13}$ and improve the quality of life of mechanically ventilated tracheostomized patients by enabling verbal communication and improving swallowing. ${ }^{13-16}$ However, the impact of speaking valves on the mobility of ICU patients remains unclear. Thus, we sought to evaluate the changes in mobility performance with the use of speaking valves in tracheostomized subjects.

\section{Methods}

This cohort study took place in a medical-surgical ICU (31 beds) at Moinhos de Vento Hospital, a private hospital in southern Brazil. Consecutive patients who were tracheostomized and weaned from mechanical ventilation between April 2016 and May 2018 were considered for inclusion in the study if they were able to tolerate a speaking valve (PMV-N007, Passy-Muir, Irvine, California) for a minimum of $30 \mathrm{~min}$, as jointly assessed by a speech pathologist and a respiratory therapist. Patients were excluded if they had significant language or cognitive deficits or were in exclusive palliative care.

\section{Data and Instruments Collected}

Demographic data, comorbidities, cause of ICU admission, ICU length of stay, duration of mechanical ventilation before tracheostomy, and days free from mechanical ventilation after tracheostomy were collected. Mobility status was evaluated by daily measurements of the Perme Intensive Care Unit Mobility Score, ${ }^{17,18}$ an instrument that objectively measures the mobility of ICU patients, starting with the ability to follow commands and culminating in the distance walked in $2 \mathrm{~min}$. The instrument is scored from 0 to 32 and includes 15 items grouped into 7 categories: mental status, potential mobility barriers, functional strength, bed mobility, transfers, gait (with or without assistive devices), and endurance. A high score indicates high mobility, whereas a lower scores indicates low mobility and a greater need for assistance.

Motor rehabilitation is standardized in our ICU in a progressive multistep program that begins with 15 passive range-of-motion exercises, with each limb joint exercised once every weekday by physiotherapists to comatose or sedated patients, followed by passive or active exercises and then fully active muscle exercises, transfer to the edge of the bed or to a chair, standing, and walking. Respiratory

\section{QUICK LOOK}

\section{Current knowledge}

A speaking valve is a one-way valve that blocks expiration through the tracheostomy tube, redirecting air flow through the upper airway to enable functional use of the glottis in tracheostomized patients. These valves have the potential to improve respiratory mechanics as well as the quality of life for tracheostomized and mechanically ventilated patients by enabling verbal communication and improving swallowing.

\section{What this paper contributes to our knowledge}

Early mobilization is part of the rehabilitation process for critically ill patients and is currently considered a means of preventing ICU-acquired muscle deterioration and worsening of physical function. Speaking valves placed in tracheostomized subjects immediately after the cessation of mechanical ventilation improved mobility.

physiotherapy is also standardized in our ICU. In each session, mechanically ventilated patients receive compression and manual vibration maneuvers during $5 \mathrm{~min}$ on each side of the thorax, with the subject positioned in the right and left lateral decubitus positions. After the intervention, auscultation and verification of the ventilator waveforms occurs to certify the absence of secretion in the patients, followed by manual hyperinflation with a manual resuscitator. The procedure is finalized with suctioning of the orotracheal tube $5 \mathrm{~min}$ after the procedure is completed.

Following human ethics approval by the Institutional Review Board, we conducted this prospective observational study using speaking valves in tracheostomized subjects. The use of speaking valves is part of the daily practice of the ICU; therefore, a waiver was granted. The study was conducted in accordance with the ethical standards established in the 1964 Declaration of Helsinki.

\section{Statistical Analysis}

Continuous variables were expressed as mean $\pm \mathrm{SD}$, and categorical variables were expressed as absolute (and relative) frequencies. Perme scores were presented as median (interquartile range) according to group/time and analyzed with generalized linear mixed models considering the individual dependence into the time and group. The level of significance was set at $P<.05$. All statistical analyses were conducted using Stata 12.0 (StataCorp, College Station, Texas).

\section{Results}

During the study period, 63 patients were tracheostomized. Patients with language $(n=2)$ or cognitive 
Table 1. Characteristics of Subjects

\begin{tabular}{|c|c|c|c|c|c|c|c|}
\hline Subjects & Gender & $\begin{array}{l}\text { Age, } \\
\text { y }\end{array}$ & $\begin{array}{l}\text { Cause of Mechanical } \\
\text { Ventilation }\end{array}$ & $\begin{array}{l}\text { Charson Comorbidity } \\
\text { Index }\end{array}$ & $\begin{array}{c}\text { Duration of Mechanical Ventilation } \\
\text { Before Tracheostomy, d }\end{array}$ & $\begin{array}{l}\text { Ventilator-Free Days } \\
\text { Post-Tracheostomy, d }\end{array}$ & $\begin{array}{l}\text { ICU Length of } \\
\text { Stay, d }\end{array}$ \\
\hline Subject 1 & Female & 72 & COPD exacerbation & 4 & 12 & 6 & 22 \\
\hline Subject 2 & Female & 80 & Pneumonia & 3 & 11 & 5 & 20 \\
\hline Subject 3 & Female & 67 & Abdominal sepsis & 4 & 10 & 6 & 25 \\
\hline Subject 4 & Male & 58 & Urinary sepsis & 2 & 13 & 7 & 32 \\
\hline Subject 5 & Female & 66 & Trauma & 1 & 5 & 4 & 16 \\
\hline Subject 6 & Male & 68 & Abdominal sepsis & 5 & 8 & 10 & 28 \\
\hline Subject 7 & Male & 79 & COPD exacerbation & 5 & 12 & 9 & 27 \\
\hline Subject 8 & Male & 80 & Pneumonia & 6 & 11 & 9 & 26 \\
\hline Subject 9 & Male & 85 & Pneumonia & 5 & 13 & 7 & 33 \\
\hline Subject 10 & Female & 80 & Pneumonia & 5 & 10 & 6 & 24 \\
\hline Subject 11 & Female & 81 & COPD exacerbation & 4 & 15 & 7 & 31 \\
\hline Subject 12 & Male & 48 & ARDS & 2 & 7 & 5 & 19 \\
\hline Subject 13 & Male & 37 & Gravis myasthenia & 5 & 6 & 12 & 24 \\
\hline Subject 14 & Female & 55 & Abdominal sepsis & 5 & 9 & 10 & 29 \\
\hline Subject 15 & Female & 50 & Pneumonia & 5 & 9 & 9 & 30 \\
\hline Subject 16 & Male & 49 & Trauma & 1 & 6 & 4 & 18 \\
\hline Subject 17 & Male & 55 & Pneumonia & 3 & 7 & 6 & 22 \\
\hline Subject 18 & Male & 61 & Pneumonia & 3 & 8 & 5 & 24 \\
\hline
\end{tabular}

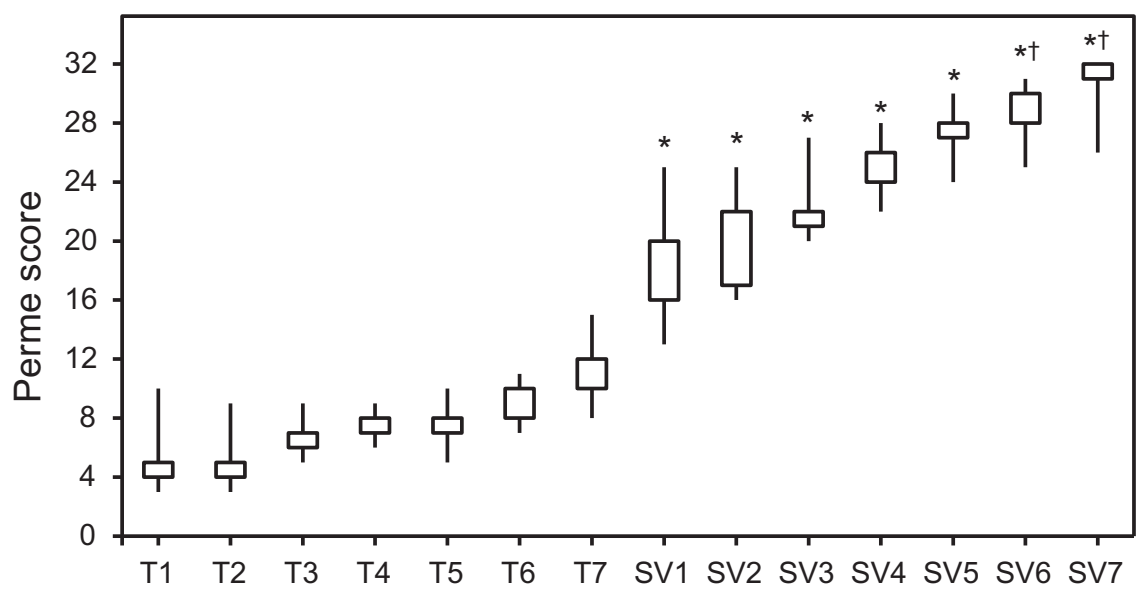

Fig. 1. Evolution of Perme scores during the period before speaking valve introduction $(T)$ and after speaking valve introduction (SV). Error bars indicate the most extreme data point (no more than $2.0 \times \mathrm{IQR}$ ). ${ }^{*} P<.01$ compared with $(\mathrm{T})$ period. $\dagger P<.01$ compared with (SV) period. IQR = interquartile range.

( $n=36)$ deficits, or who were undergoing exclusive palliative care $(n=7)$ were excluded; 18 subjects were enrolled in the study. The mean age of the subjects in the study was $64.6 \pm 14.2$ y (55.5\% were male), and the most common reason for ICU admission was pneumonia $(n=7$; $38.8 \%$ ) (Table 1).

Figure 1 shows the improvement in subjects' mobility immediately after the introduction of a speaking valve. The median Perme score $7 \mathrm{~d}$ before speaking valve use was 11.3 (interquartile range 10.1-12.0), and the median Perme score 1 day after introduction of the valve was 18.2 (interquartile range 16.2-20.1) $(P<.01)$. In evaluating the categories of the subjects' Perme scores, changes in "transfer category" scores (ie, characterized by "sit to stand," "static standing balance once standing position is established," and "transfer from bed to chair OR chair to bed") were largely responsible for increased mobility (Table 2).

\section{Discussion}

The major finding of this study was that the use of speaking valves in tracheostomized subjects immediately after cessation of mechanical ventilation improved their mobility as measured by the Perme scale. 


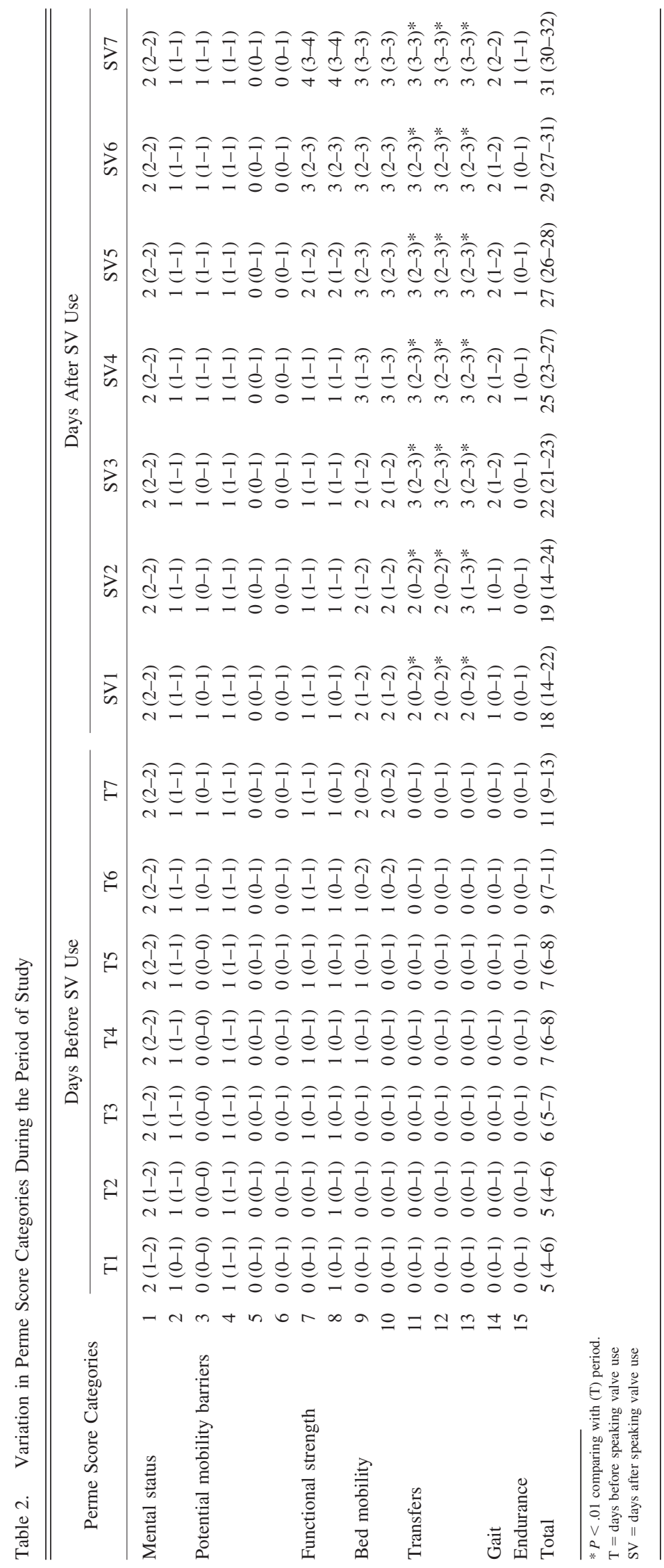


The use of speaking valves is now routine practice and has become increasingly common with very sick tracheostomized patients. ${ }^{19,20}$ Tracheostomized patients have communication difficulties, which is a major source of frustration for them while ventilated in the ICU. This has reportedly led to social withdrawal, reduced motivation to participate in care, depression, poor sleep, and increased anxiety and stress levels..$^{15,20,21}$ Patients have reported a sense of renewed autonomy and freedom from social isolation when able to speak again. In addition, patients' ability to speak makes it easier for the ICU team to care for them. ${ }^{21}$ However, the use of a speaking valve requires cuff deflation, which creates a leak in the ventilatory system. This is thought to cause lung decruitment, which can reduce end-expiratory lung volumes and lead to alveolar collapse and atelectasis. This can prolong ventilator use and thus the duration of ICU care. ${ }^{14}$ However, others have disputed this risk. ${ }^{22}$

A number of investigators have suggested that speaking valves should be used only with patients who are awake, responsive, and attempting to communicate. ${ }^{15,19,20}$ Such patients must be able to exhale around the tracheostomy tube and through the upper airway, be able to tolerate cuff deflation, and be medically stable. Tracheostomized patients first recover their mobility, then their ability to swallow, and finally their ability to speak. ${ }^{16}$ To our knowledge, this is the first study to evaluate the relationship between speaking valves and mobility in mechanically ventilated ICU subjects. When a patient attempts to move, the Valsalva maneuver is generated; the one-way speaking valve allows recruitment of abdominal muscles and increases intra-abdominal pressure while blocking expiratory flow, simulating glottis closure. ${ }^{23}$ This substantially improves the quality of movement requiring the contraction of abdominal muscles, such as bed mobility, transfers, and walking (all Perme scale domains). Thus, speaking valve use can facilitate early mobilization, a practice associated with shortened periods of mechanical ventilation and functional improvement in patients in the ICU. 5,24

The primary limitation of our study is its nonrandomized design; we did not have a control group for comparison. Second, the Perme scale has not been validated for tracheostomized subjects. The strength of our findings comes mainly from the novelty of the investigation. To our knowledge, the relationship between mobility and speaking valve use has not yet been evaluated.

\section{Conclusions}

Speaking valves have the potential to improve respiratory mechanics as well as the quality of life for tracheostomized and mechanically ventilated patients by enabling verbal communication and improving swallowing. Besides that, when started soon after the cessation of mechanical ventilation in tracheostomized subjects, a speaking valve can improve their capacity for mobility.

\section{REFERENCES}

1. Roberson AR, Starkweather A, Grossman C, Acevedo E, Salyer J. Influence of muscle strength on early mobility in critically ill adult patients: systematic literature review. Hear Lung J Acute Crit Care 2018; 47(1):1-9.

2. Doiron KA, Hoffmann TC, Beller EM. Early intervention (mobilization or active exercise) for critically ill adults in the intensive care unit. Cochrane Database Syst Rev 2018;3:CD010754.

3. Rosenthal MD, Kamel AY, Rosenthal CM, Brakenridge S, Croft CA, Moore FA. Chronic critical illness: application of what we know. Nutr Clin Pract 2018;33(1):39-45.

4. Batt J, Herridge M, dos Santos C. Mechanism of ICU-acquired weakness: skeletal muscle loss in critical illness. Intensive Care Med 2017;43(12):1844-1846.

5. Verceles AC, Wells CL, Sorkin JD, Terrin ML, Beans J, Jenkins T, et al. A multimodal rehabilitation program for patients with ICU acquired weakness improves ventilator weaning and discharge home. J Crit Care 2018;47:204-210.

6. Fossat G, Baudin F, Courtes L, Bobet S, Dupont A, Bretagnol A, et al. Effect of in-bed leg cycling and electrical stimulation of the quadriceps on global muscle strength in critically ill adults: a randomized clinical trial. JAMA 2018;320(4):368-378.

7. Paton M, Lane R, Hodgson CL. Early mobilization in the intensive care unit to improve long-term recovery. Crit Care Clin 2018;34(4):557-571.

8. Fuest K, Schaller SJ. Recent evidence on early mobilization in critical-Ill patients. Curr Opin Anaesthesiol 2018;31(2):144150 .

9. Tipping CJ, Harrold M, Holland A, Romero L, Nisbet T, Hodgson CL. The effects of active mobilisation and rehabilitation in ICU on mortality and function: a systematic review. Intensive Care Med 2017;43(2):171-183.

10. Lichtman SW, Birnbaum IL, Sanfilippo MR, Pellicone JT, Damon WJ, King ML. Effect of a tracheostomy speaking valve on secretions, arterial oxygenation, and olfaction: a quantitative evaluation. J Speech Lang Hear Res 1995;38(3):549.

11. Hess DR. Facilitating speech in the patient with a tracheostomy. Respir Care 2005;50(4):519-525.

12. Prigent H, Orlikowski D, Blumen MB, Leroux K, Legrand L, Lejaile $\mathrm{M}$, et al. Characteristics of tracheostomy phonation valves. Eur Respir J 2006;27(5):992-996.

13. Sutt AL, Caruana LR, Dunster KR, Cornwell PL, Anstey CM, Fraser JF. Speaking valves in tracheostomised ICU patients weaning off mechanical ventilation - do they facilitate lung recruitment? Crit Care 2016;20(1):1-9.

14. Sutt AL, Cornwell P, Mullany D, Kinneally T, Fraser JF. The use of tracheostomy speaking valves in mechanically ventilated patients results in improved communication and does not prolong ventilation time in cardiothoracic intensive care unit patients. J Crit Care 2015;30(3):491494.

15. Freeman-Sanderson AL, Togher L, Elkins MR, Phipps PR. Return of voice for ventilated tracheostomy patients in ICU: a randomized controlled trial of early-targeted intervention. Crit Care Med 2016;44(6): 1075-1081.

16. Barros APB, Portas JG, Queija DS. Tracheotomy implication upon communication and swallowing. Rev Bras Cir Cabeça Pescoço 2009; 38(3):202-207.

17. Perme C, Nawa RK, Winkelman C, Masud F. A tool to assess mobility status in critically ill patients: the Perme Intensive Care 


\section{Speaking Valves and Mobility}

Unit Mobility Score. Methodist Debakey Cardiovasc J 2014;10(1): 41-49.

18. Kawaguchi YMF, Nawa RK, Figueiredo TB, Martins L, PiresNeto RC. Perme Intensive Care Unit Mobility Score and ICU Mobility Scale: translation into Portuguese and cross-cultural adaptation for use in Brazil. J Bras Pneumol 2016;42(6):429434.

19. Sutt A-L, Fraser JF. Speaking valves as part of standard care with tracheostomized mechanically ventilated patients in intensive care unit. J Crit Care 2015;30(5):1119-1120.

20. Sutt AL, Fraser JF. Patients want to be heard-loud and clear! Crit Care 21(1):4-5, 2017.

21. Sutt AL, Anstey CM, Caruana LR, Cornwell PL, Fraser JF. Ventilation distribution and lung recruitment with speaking valve use in tracheostomised patient weaning from mechanical ventilation in intensive care. J Crit Care 2017;40:164-170

22. Hernandez G, Pedrosa A, Ortiz R, Cruz Accuaroni MM, Cuena R, Vaquero Collado $\mathrm{C}$, et al. The effects of increasing effective airway diameter on weaning from mechanical ventilation in tracheostomized patients: a randomized controlled trial. Intensive Care Med 2013;39(6):1063-1070.

23. Hacket DA, Chow CM. The Valsalva maneuvers: Its effect on intraabdominal pressure and safety issues during resistance exercise. J Strength Cond Res 2013;8:2338-2345.

24. Schweickert WD, Pohlman MC, Pohlman AS, Nigos C, Pawlik AJ, Esbrook CL, et al. Early physical and occupational therapy in mechanically ventilated, critically ill patients: a randomised controlled trial. Lancet 2009;373(9678):1874-1882.

This article is approved for Continuing Respiratory Care Education credit. For information and to obtain your CRCE

(free to AARC members) visit

www.rcjournal.com 